\title{
Object and Action Naming in Children With Specific Language Impairment
}

\author{
Li Sheng and \\ University of Texas at Austin
}

Karla K. McGregor

University of lowa

\begin{abstract}
Purpose-In this study, the authors aimed to examine the accuracy, latency, and errors of noun (object) and verb (action) naming in children with and without specific language impairment (SLI) and to determine whether children with SLI have a particularly large noun-verb performance gap.

Method-Children with SLI, age-matched peers (AM), and expressive vocabulary-matched peers (VM) named 120 matched object and action pictures in a computerized confrontation naming task.
\end{abstract}

Results-The SLI and VM groups demonstrated comparable naming latency and accuracy; both were slower and less accurate than the AM group. Object naming was more accurate than action naming in the SLI and VM groups; their noun-verb performance gaps were comparable. Object naming was faster than action naming in all children. In comparison with the AM group, the SLI group made proportionally fewer taxonomic errors and more omission errors when naming objects, and fewer misperception errors when naming actions.

Conclusions-The naming abilities of children with SLI, although deficient given their chronological age, are commensurate with their vocabulary level. Their naming errors suggest immaturities in semantic representation. Action naming is significantly more difficult than object naming, but the noun-verb gap that characterizes the performance of children with SLI is appropriate for their vocabulary level.

\section{Keywords}

naming; specific language impairment; objects; actions; nouns; verbs

\begin{abstract}
Nouns are easier than verbs. Studies have shown that children learn nouns more quickly than they do verbs (Bornstein et al., 2004; Childers \& Tomasello, 2002; Gentner, 2006; Imai et al., 2008; Seston, Golinkoff, Ma, \& Hirsh-Pasek, 2009), and adults (Szekely et al., 2005) and children (Davidoff \& Masterson, 1996; Kauschke, Lee, \& Pae, 2007;Masterson,Druks,\&Gallienne, 2008; Schelletter, 2005) demonstrate a reliable noun advantage on naming tasks. If verbs invoke high processing demands (Tomasello \& Kruger, 1992), it follows that children with specific language impairment (SLI), a population that demonstrates limited processing capacities (see, e.g., Ellis Weismer \& Evans, 2002; Montgomery, 2002; Windsor, 2002), might present with exaggerated noun-verb gaps. However, support for this hypothesis is equivocal. In this study, we compared the object
\end{abstract}


noun and action verb naming responses of children with and without SLI with a primary goal of determining whether those with SLI have a disproportional noun-verb performance gap. With a clearer description of the gap, we can refine our knowledge of the SLI profile. Moreover, we may make better informed choices about targets of intervention-specifically, whether to focus equally on nouns and verbs or whether to place more emphasis on verbs.

\section{Semantic and Conceptual Differences Between Nouns and Verbs}

Gentner $(1981,1982,2006)$ hypothesized two bases of the noun-verb gap. The natural partitions hypothesis attributes the distinction between nouns and verbs to semantic and conceptual differences. Concrete nouns are objects or beings that are cohesive, perceptually stable, and naturally individuated. In contrast, verbs-even fairly concrete ones-refer to changes of state that are transient and not easily parsed from the scene. The linguistic relativity hypothesis posits that noun semantics are relatively transparent and stable across different languages. By comparison, verbs encode information about the path, manner, or instrument of actions, and the question of exactly which aspects of the actions are to be attended and lexicalized in a language is cross-linguistically variable.

Research by Gentner $(1981,1982)$ and others (Bates et al., 1994; Fenson et al., 1994; Jackson-Maldonado et al., 1993) on the composition of children's early lexicon suggests that nouns are learned earlier and take up a larger proportion of children's first words than verbs. These findings have been challenged in studies of verb-friendly languages such as Mandarin and Korean (e.g., Kim, McGregor, \& Thompson, 2000; Tardif, 1996), where the noun advantage is significantly reduced or even absent. However, the method of data collection has a significant impact on the outcome (Tardif, Gelman, \&Xu, 1999). Book reading activities are conducive to the production of nouns; in contrast, toy play activities tend to elicit a higher number of verbs. Studies using parental checklists-a more comprehensive observational technique-favor the claim of a universal noun advantage (Bornstein et al., 2004; Tardif et al., 1999).

Novel word acquisition studies also suggest a noun advantage. Novel nouns are learned more readily than novel verbs by children who speak languages such as English, Chinese, and Japanese (Childers \& Tomasello, 2002; Dockrell, Braisby, \& Best, 2007; Imai et al., 2008; Rice, Buhr, \& Nemeth, 1990). Further, after verbs have entered children's vocabularies, learning their full meaning takes a protracted period of time. For example, Seston and colleagues (2009) found that even 6- and 8-year-olds, who have considerable verb knowledge, still found it difficult to extend the meaning of open-instrument verbs (e.g., chop, scrub, sweep, write). Of course, this slow process is, to some extent, also true for nouns (Ameel, Malt, \& Storms, 2008).

Although Gentner's theoretical framework pertains to the timing of the acquisition of nouns and verbs, it can also account for the ways in which these two classes of words are processed during tasks such as picture naming. In a study examining the naming of 520 object and 275 action pictures among adults, Szekely et al. (2005) found that differences in naming difficulty (indexed by name agreement and naming latency) remained after matching object and action targets on frequency, age of acquisition (AoA), and picture complexity. At the same time, objects and actions matched for naming difficulty differed on lexical and pictorial properties. These authors suggested that the deep-seated semantic and conceptual differences between nouns and verbs may have contributed to the differences in naming performance. 


\section{Object and Action Naming in Typically Developing Children}

To date, only a handful of studies have directly compared object and action naming in children (Davidoff \& Masterson, 1996; Kauschke et al., 2007; Masterson et al., 2008; Schelletter, 2005). These studies included children who spoke English, German, Turkish, and Korean. Similar to adults, children were more accurate and faster in naming objects than in naming actions. Also apparent was a developmental change in the size of the noun-verb gap. Specifically, Schelletter (2005) found that the youngest group of participants (4- to 5year-olds) demonstrated a bigger noun-verb gap than the two older groups (5- to 6-year-olds and 6- to 7-year-olds). Similarly, in Experiment 1 of the Masterson et al. (2008) study, the 3year-olds made more errors on actions than on objects, but the 5-year-olds made a similar proportion of errors on both.

Two studies investigated errors of naming in typically developing children. Davidoff and Masterson (1996) identified five types of errors: (a) circumlocutions (semantically informative descriptions); (b) semantic errors (superordinate, coordinate, and associative errors); (c) visual errors (based on a salient visual aspect of the picture that was semantically unrelated to the target); (d) refusals; and (e) unrelated errors. They found that the most common errors in object naming were semantic (50.8\%), followed by refusals (24.4\%). In contrast, action pictures most often elicited circumlocutions (31.7\%), visual errors (28.9\%), and semantic errors (26.5\%). Masterson et al. (2008) coded four types of naming errors among 3-year-olds and 5-year-olds: (a) semantic errors (which included coordinate, superordinate, and associative errors); (b) visual errors (which included misperceptions such as calling a biscuit a button and misinterpretations such as calling a wig a judge); (c) other errors (which included synonyms, noun-verb and verb-noun errors, circumlocutions, mixed errors, and unrelated errors); and (d) omission errors (i.e., don't know). The 3-year-olds had a higher percentage of omissions (37.5\%) than the 5-year-olds (22\%). Both groups had a high percentage of semantic errors (28.5\% for the 3-year-olds and $37 \%$ for the 5-year-olds), among which coordinates were the most frequent. With regard to word class differences, the 3-year-olds showed largely similar error patterns for both object and action targets; the 5year-olds showed more semantic errors for actions (43\%) than for objects (31\%) and more omissions for objects (28\%) than for actions (16\%).

\section{Picture Naming in Children With SLI}

To the best of our knowledge, no existing studies have directly compared object and action naming in children with language impairment. Previous studies either focused solely on object naming (Lahey\&Edwards, 1996, 1999; Leonard, Nippold, Kail, \& Hale, 1983; McGregor, Newman, Reilly, \& Capone, 2002) or used unmatched noun and verb stimuli (Dockrell, Messer,\&George, 2001; McGregor, 1997). This literature demonstrates that children with SLI have deficits in decontexualized picture naming tasks. Compared with age-matched peers, they exhibit significantly lower naming accuracy and slower naming speed (Lahey \& Edwards, 1996, 1999; Leonard et al., 1983; McGregor et al., 2002).

Differences in naming error profiles are also evident. In a study of object naming, Lahey and Edwards (1999) found a higher proportion of semantic associate errors (e.g., dust for broom), phonological errors (e.g., pumplin for pumpkin), and don't know errors in the SLI group than in the age-matched control group. McGregor (1997) examined naming errors in children with word finding difficulties (WFDs; a subtype of language impairment with word retrieval difficulties as the primary phenotype) on the noun- and verb-naming subtests of the Test of Word Finding (German, 1989). The children with WFDs produced more errors on both subtests than did the age-matched control group. The majority of errors in both groups bore semantic relations to the targets, suggesting an early and robust organization of words 
in a network of related information. There was a notable exception to the overall similarity in error profiles: On the verb-naming subtest, $36 \%$ of the errors in the WFD group were unrelated to the targets; in contrast, only $11 \%$ of the errors in the control group were this type. In another study, Dockrell et al. (2001) found that children with WFDs made proportionally more phonological errors on object naming and more unrelated and semantically nonspecific errors (e.g., doing for sewing, moving for crawling) on action naming than did their age-matched peers. There was also a shift in error distribution between the two classes of words in both groups: The majority of object naming errors were semantic in nature; the majority of action naming errors belonged to the "other" category, which encompassed circumlocutions, nonsense words, descriptions of the items in the picture, or naming responses in which links between target and answer were indirect or thematic. In all three studies (Dockrell et al., 2001; Lahey \& Edwards, 1999; McGregor, 1997), the authors suggested that differences in error profiles can be attributed to underelaborated and poorly differentiated semantic storage in the children with language impairment.

\section{Verb Learning in SLI}

Because actions are transient and have less clearly defined boundaries than objects (Gentner, 2006), verb learning places higher demands on children's attentional, representational, and linguistic capacities (Tomasello \& Kruger, 1992). This should be especially true of children with SLI, who demonstrate more limited processing capacities in a variety of verbal tasks (e.g., Ellis Weismer\& Evans, 2002; Montgomery, 2002; Windsor, 2002). Moreover, because the meanings of many verbs ostensibly cannot be learned from exposure to events, the learner must rely on morphosyntactic cues and sentence frames (i.e., syntactic bootstrapping) to narrow down the meaning of a verb (Gleitman, 1990). This process should further compromise verb learning among children with SLI, as these children are known for their difficulties with morphosyntax (Rice, 2003). Nevertheless, current evidence of exaggerated noun-verb gaps among children with SLI is equivocal.

It is unclear whether children with SLI have particular difficulties with novel verb learning. On the one hand, Oetting, Rice, and Swank (1995) found that children with SLI (aged 6;0$8 ; 0$ [years;months]) made significantly less gain than did their age-matched peers in the learning of action words but not in words that referred to objects, attributes, or affective states. On the other hand, Leonard and Schwartz (1985) found that children with SLI (aged $2 ; 8-3 ; 4)$ performed better in action word learning than did their language-matched controls (aged 1;5-2;0). However, this performance advantage in the children with SLI was difficult to evaluate because an age-matched control group was not included. It is possible that the older age of the SLI group and their longer experience with relational terms might have led to this difference.

A more recent investigation by Alt, Plante, and Creusere (2004) suggested that children with SLI do not have exaggerated difficulties with verb learning. In this study, the authors investigated the learning of semantic features and lexical labels by children with and without SLI (ages 4;0-6;0). Both groups showed a learning advantage for nouns over verbs in both lexical label recognition and semantic feature mapping. On the label recognition task, the children with SLI showed poorer learning than did their age-matched peers for both nouns (a mean difference of 5.04) and verbs (a mean difference of 4.11). On the semantic feature mapping task, the performance deficit in children with SLI was larger for nouns (a mean difference of 4.23) than for verbs (a mean difference of 2.23). Therefore, word learning was difficult for children with SLI; however, verb learning was not necessarily more problematic than noun learning in these children. This view was further supported by Eyer and colleagues (2002), who found that preschoolers - whether or not they have language impairment-had difficulty using morphosyntactic information to bootstrap verbs. Taken 
together, it remains inconclusive whether children with SLI have greater difficulties in verb acquisition than their typically developing peers.

\section{Verb Use in SLI}

Various studies have focused on the use of verbs (rather than novel word acquisition) in children with SLI. For instance,Watkins, Rice, and Moltz (1993) found that children with SLI had a lower verb diversity than age-matched peers and mean length of utterance (MLU)-matched peers. Conti-Ramsden and Jones (1997) found that compared with MLUmatched peers, children with SLI used nouns more frequently and with a larger diversity but used verbs less frequently and with a smaller diversity.

Researchers have also examined the use of a subcategory of verbs-namely, general allpurpose (GAP) verbs. One line of research (Conti-Ramsden \& Jones, 1997; Rice\&Bode, 1993; Thordardottir \& Ellis Weismer, 2001; Watkins et al., 1993) defined GAP verbs as verbs that occur at a higher-than-average frequency in children's spontaneous language samples. These studies, in aggregate, suggest that children with SLI are indistinguishable from controls in high-frequency verb use and that extensive use of high-frequency verbs is characteristic of typical development (but see Rice \& Bode, 1993, for a different argument).

Two other studies defined GAP verbs on the basis of semantic specificity rather than frequency of occurrence (Dockrell et al., 2001; Kelly, 1997). In a previously reported study, Dockrell et al. (2001) found that GAP verb substitutions were more common in the children with WFDs and language-matched peers than in age-matched peers, suggesting that the semantic domains of verbs were less clearly delineated in children who were linguistically less mature. However, this may not be true of children with SLI more generally defined: Kelly (1997) found that children with SLI produced a lower proportion of GAP verbs (e.g., go, move, make) than did their age-matched and MLU-matched peers in a study that elicited labels for action scenarios.

To summarize, children with SLI are less accurate and slower at confrontation naming than their unaffected peers matched for age. These children make the same types of naming errors as their peers, although deviations in error rate suggest inadequate lexical-semantic storage. Despite the argument that verb learning poses extraordinary difficulties in children with SLI - a population known for their morphosyntactic deficits and processing limitations - evidence from novel word acquisition studies is inconclusive. In addition, although children with SLI appear to have a lower verb diversity (Conti-Ramsden \& Jones, 1997; Watkins et al., 1993) than peers, frequency-based analyses of GAP verb usage do not differentiate children with SLI from typically developing peers (Thordardottir \& Ellis Weismer, 2001; Watkins et al., 1993). Alternatively, semantically based analyses of GAP verb usage suggest a weaker reliance on GAP verbs in a relatively open-ended task (scene description; Kelly, 1997) and a heavier reliance on GAP verbs in a more constrained task (picture naming; Dockrell et al., 2001) by children with SLI than by age-matched peers.

\section{The Present Study}

A review of the literature suggests a robust and possibly universal gap in noun-verb acquisition as well as in object-action naming. The gap likely reflects semantic and conceptual differences between nouns and verbs. Although there is consensus that the learning and processing of verbs poses a bigger challenge than that of nouns for all children (Gentner, 1982; Tomasello\&Kruger, 1992), what remains unclear is whether children with SLI experience exacerbated problems with verb naming that surpass their general difficulties with vocabulary. 
In the present study, we aimed to further our understanding of naming abilities in children with SLI. This study differs from previous investigations in two ways. First, we examined the accuracy, latency, and error patterns in the naming of a set of carefully matched object and action stimuli, thereby providing a direct comparison between these two classes of words in children with SLI. Second, we included both an age-matched group and a vocabulary-matched group. Because the noun-verb gap diminishes with development, children with SLI may appear to have an exaggerated gap relative to their chronological age-matched peers. The critical test, however, is whether they have an exaggerated gap given their own overall level of development. This is where the vocabulary-matched peers were particularly helpful. The inclusion of the vocabulary-matched peers allowed us to see whether the noun-verb gap in children with SLI is appropriate for their vocabulary level.

The storage hypothesis (Kail \& Leonard, 1986) and the unified model of SLI (Rice, 2003) both suggest that in the domain of vocabulary development, this disorder is manifested as a general delay. Therefore, we hypothesized that children with SLI would demonstrate naming deficits that are commensurate with their general vocabulary immaturities. Specifically, we predicted that the children with SLI would be less accurate and slower than their agematched peers but comparable to their vocabulary-matched peers in picture naming.

Second, based on previous investigations (e.g., Dockrell et al., 2001; Lahey\&Edwards, 1999; McGregor, 1997), we predicted that the children with SLI would make similar types of errors as their peers. However, differences in error rates may exist. Specifically, the SLI group may show proportionally more unrelated errors, GAP verb errors, and omission errors than the age-matched group.

Third, guided by Gentner's $(1982,2006)$ developmental theory as well as by empirical findings (e.g., Davidoff \& Masterson, 1996; Masterson et al., 2008; Schelletter, 2005),we predicted that object naming would be easier than action naming and that this noun advantage would be greater among the two groups who were linguistically less maturenamely, children with SLI and vocabulary-matched peers- than among the age-matched peers. We predicted that the SLI and vocabulary-matched groups would present with comparable noun-verb gaps.

Fourth, we predicted differential error patterns for object and action naming. Because hierarchical organization of nouns is in place quite early in development (McGregor, 1997; McGregor \& Waxman, 1998), we expected that object naming would be more likely to obey the taxonomic constraints of object hierarchies-hence, a higher rate of semantic taxonomic errors for objects than for actions. Alternatively, because verbs are inherently more complex and ambiguous (Gentner, 2006), action naming errors would be more likely to occur due to failures of interpretation-hence, a higher rate of visual misinterpretation errors or unrelated errors for actions than for objects.

\section{Method}

\section{Participants}

Forty-two children took part in the present study (see Table 1). Their recruitment and testing was conducted in accordance with procedures approved by the University of Iowa Institutional Review Board (IRB). These children also participated in a word association task reported in Sheng and McGregor (2010). A battery of standardized tests-including measures of nonverbal performance, phonological memory, expressive syntax, narrative comprehension and production, and receptive and expressive vocabulary-was administered to all children. Fourteen children met the criteria of SLI, 14 children served as age-matched (AM) controls, and 14 children served as expressive vocabulary-matched (VM) controls. 
The participants in the SLI and VM groups were matched on the basis of raw scores on the Expressive Vocabulary Test (EVT; Williams, 1997). Because all children were at least age $5 ; 0$, the Synonym section of the EVT was administered to each participant. There were 152 items in this section, among which 62 items elicited synonyms for nouns, 38 items elicited synonyms for verbs, 47 items elicited synonyms for adjectives, and five items elicited synonyms for adverbs. Detailed information about the children and the vocabulary-matching procedures can be found in Sheng and McGregor (2010). All children in the SLI group had a diagnosis of language impairment made by a licensed speech-language pathologist (SLP) and were enrolled in therapy. The SLI group scored statistically lower than did their AM peers on all language measures. They also had lower maternal education level, $F(2,39)=$

5.76, $p=.006, \mathrm{\eta}_{\mathrm{p}}^{2}=.23$, and performance IQ scores, $F(2,39)=3.89, p=.03, \mathrm{\eta}_{\mathrm{p}}^{2}=.17$, than the control groups (see Table 1 for $M \mathrm{~s}$ and $S D \mathrm{~s}$ ). Maternal education and performance IQ were included in subsequent analyses as covariates.

\section{Stimuli}

The stimuli consisted of black-and-white line drawings of 60 objects and 60 actions (available from the International Picture Naming Project; Szekely et al., 2004). We took steps to control for properties of the word and picture stimuli that may affect naming performance. First, we used pre-established procedures (Carroll \& White, 1973; Sheng, McGregor,\&Marian, 2006) and collected AoA estimates for these words from 14 adult native speakers of English. According to these adults, 110 of the words were acquired prior to age 5;0, and only five nouns and five verbs were acquired between ages 5;0 and 6;0. Because adult AoA estimates are significantly correlated with the actual age at which children acquire words (Morrison, Chappell, \& Ellis, 1997), there is reason to believe that the participants in this study should have at least some preliminary representations of most of these targets. The object words $(M=3.36, S D=1.04$, in years) and action words ( $M=$ $3.27, S D=1.07)$ were matched on AoA, $t(118)=0.46, p=.65$.

Next, log word frequency values were calculated for all but eight of the words using a database of spontaneous language samples of first-grade children (Moe, Hopkins, \& Rush, 1982). The missing words included three object targets and five action targets. The object $(M=1.20, S D=0.70)$ and action $(M=1.18, S D=0.74)$ targets were of comparable frequency of occurrence, $t(110)=0.15, p=.88$. Third, familiarity ratings of the words were obtained from Nusbaum, Pisoni, and Davis (1984). All words had a familiarity rating of 6.5 or higher on a 7-point scale $(1=$ unknown, $7=$ well known $)$, and the object $(M=6.96, S D=$ $0.10)$ and action $(M=6.97, S D=0.09)$ targets were matched on familiarity, $t(118)=0.16, p$ $=.87$. Fourth, semantic set size, which refers to the number of words that are frequently associated with a given word, was derived from Nelson, McEvoy, and Schreiber (1998) for all but two object and four action targets. The object $(M=14.60, S D=4.87)$ and action $(M$ $=14.41, S D=4.32)$ targets were matched on semantic set size, $t(112)=0.22, p=.82$. Finally, word length, which refers to the number of phonemes per word, was not perfectly matched between the object $(M=3.72, S D=0.61)$ and action $(M=3.55, S D=0.67)$ targets $(p<.5), t(118)=1.42, p=.16$. This factor was subsequently included as a covariate.

We also controlled for the presence/absence of a fricative in the word-initial position, a factor that reportedly influences the time required for a response to register on a voice key (Szekely et al., 2004, 2005). Twenty-one of the object targets and 19 of the action targets began with a fricative. Among the 60 object targets, 17 were animate objects. With one exception (i.e., kneel), all action words could be used transitively or intransitively, according to the Merriam-Webster Online Dictionary (see http://www.merriam-webster.com). 
Because naming performance is influenced by the clarity of picture stimuli, all pictures included in the present study had name agreement rates (an index of picture clarity) of $80 \%$ or above, based on the naming performance of 50 adult native speakers of American English (Szekely et al., 2005). Although name agreement was high for all targets, the mean was higher for objects $(M=0.96, S D=0.05)$ than for actions $(M=0.93, S D=0.07), t(118)=$ $2.90, p=.004, d=0.51$. Visual complexity of the picture stimuli (indexed by the size of the digital file; Szekely et al., 2005) also differed significantly between the object $(M=15,531$; $S D=5,609)$ and action $(M=22,651 ; S D=7,125)$ pictures, $t(118)=6.08, p<.001, d=1.11$. The action pictures were significantly more complex than the object pictures. These two variables were also included as covariates.

\section{Procedure}

Participants were tested individually in the Word Learning Laboratory at the University of Iowa or at a place of participants' convenience. Before starting the naming task, microphone sensitivity was calibrated for each individual during a short practice session. Practice for the object naming and action naming task each involved two parts. First, five object and five action pictures not used in the actual experiment were presented on paper to each child for practice. Second, the child practiced naming pictures presented on the computer, using a different set of five objects and five actions not included in the main task. The examiner provided feedback and made corrections if necessary (e.g., "For this picture, I would say bear."). Both the simple present (e.g., cut) and the present progressive (e.g., cutting) forms of verbs were modeled and accepted as correct because of individual child preferences. During practice, the examiner instructed the child to name the picture as quickly as possible and not to say any extraneous words (e.g., "Do not say 'I think this is an $x$ '; just say ' $x$ ') or make any extraneous noises (e.g., coughing, fillers such as uhmm or ah).

During testing, the child sat in front of a laptop computer with an Audio-TechnicaATR20 microphone placed within $1 \mathrm{in}$. of his or her mouth. The pictures were imported into the EPrime (Psychology Software Tools, 2002) computer program and were presented, one at a time, on a monitor placed approximately 12 in. away from the child. A voice-activated switch with 1-ms resolution connected with the microphone, and the computer controlled the timing of presentation and generated a measurement of reaction time (RT; from onset of the picture presentation to the onset of naming response). On each trial, a 1000-Hz pure-tone beep was played for $200 \mathrm{~ms}$, followed by a 500-ms blank interval and then by the target picture. The pictures were centrally displayed ona 14-in. IBM ThinkPad T23 laptop computer screen set to $1024 \times 768$ bit-depth resolution (pictures were $300 \times 300$ pixels). The picture disappeared from the screen as soon as a response was registered by the voice key or after 5,000 ms had elapsed. The pictures were presented in four blocks of 30 pictures, grouped by word class. Short breaks were allowed between blocks. Pictures within each block were randomized and presented in a fixed order to each participant. Half the children named the objects first, and half named the actions first. The two blocks of object pictures were presented in counterbalanced order, as were the two blocks of action pictures.

An examiner was present throughout each session to (a) control the presentation of stimuli and ensure that the participant was attentive and (b) record responses for subsequent scoring. The examiner marked corresponding columns on a scoring sheet to indicate accurate naming responses, lack of response, quiet responses (i.e., ones that failed to trigger the voice key), false triggers of the voice key (due to hesitations or extraneous noise), and attention lapse. Responses that were not listed on the scoring sheet were written verbatim for later coding. Once the examiner had taken notes of the child's response and made sure that the child was paying attention, she pressed a key on the computer to advance to the next trial. Each session was also recorded using a Sony digital voice recorder. 


\section{Coding}

Naming accuracy-To be counted as an accurate naming response, the child's production had to be the lexical target or a morphological variant of the target (e.g., response/target = blew/blow; feet/foot; piggie/pig). Self-corrections within the 5-s response window that led to the targets were counted as accurate (e.g., "knife-I mean, a sword"/sword). Also included in this category were multiple-word responses that contained the lexical targets (e.g., scaring the little boy/scaring).

Naming RT-To be included in the RT analysis, a response had to correspond to the target and had to be produced without audible hesitations. By this criterion, synonyms (e.g., dribble/bounce, punt/kick) and self-corrections were excluded. However, multiple-word responses with the target occurring first were judged as valid (e.g., scaring the little boy/ scaring). False triggers, failures in triggering the voice keys, and delays due to attention lapse were excluded from the RT analysis regardless of response type. This trimming procedure was preferred over truncating data points that were above or below a certain preset number because our administration procedures allowed us to identify true outliers and preserve the genuine variability in children's naming performance. Rate of naming latency data loss/retention is presented in Table 2. Within each group, data loss due to false triggers, multiple-word responses, and attention lapse was comparable between the noun and verb classes. Alternatively, data loss due to errors of naming was twice as high for the action targets as for the object targets, resulting in a higher data retention rate for the object targets.

Naming errors-Responses deviating from the lexical targets were coded as semantic, visual, or other. A semantic error could be (a) a GAP noun-verb substitution (e.g., response/ target, man/doctor, playing ball/bouncing), in which the participant used a superordinate term to substitute for a more specific word; (b) a coordinate (e.g., wolf/goat, whistling/ blowing); or (c) a more specific (subordinate) term(e.g., cobra/snake, stirring/cooking). Together, these three error types reflected taxonomic knowledge as they related to the target at the superordinate, basic, or subordinate levels of the taxonomy. Semantic errors could also be (d) a thematically related term (e.g., dig/shovel, tired/yawning) or (e) a semantic circumlocution (e.g., horseback thing/saddle, laying on the water/floating). A visual error could be (a) a misperception of the target (e.g., fishing pole/flute, shouting/yawning) due to overall visual (but not semantic) similarity or (b) a misinterpretation, which may be a description of an irrelevant aspect of the visual scene (e.g., dummy/wig, piano sound/ playing) or a label of the agent of an action (e.g., girl/smiling) without attempting the actual target. Visual errors did not bear inherent semantic relationships with the targets. The "other" category included (a) synonyms (e.g., tortoise/turtle, dribbling/bouncing); (b) novel words or novel use of words (e.g., horse-sitter/saddle, ocean ladder/bridge, wolfing/barking, knee-walking/kneeling); (c) purely phonologically related words (e.g., knob/nail, as the two words shared the same onset and the same number of syllables); errors that bore both semantic and phonological relations to the target (e.g., foot/hoof, servant/serve; climbing/ crawling; slapping/clapping) were counted as semantic; (d) an unrelated response (e.g., fiddler/flute, avoid/suck); (e) a repetition of an earlier response (perseveration), which bore no apparent semantic, phonological, or perceptual relations to the target (e.g., hide/sleep); and (f) no response or don't know.

\section{Reliability}

To check for reliability of naming response transcription, an independent rater listened to $10 \%$ of the audio recordings and wrote down the children's productions verbatim. Point-topoint agreement on the orthographic transcription averaged $98.4 \%$ and ranged from $97.5 \%$ to $99.2 \%$. Reliability of naming error coding was verified by having a second coder blind to the identity of the children independently code the errors of four children from each group. 
Agreement ranged from $73 \%$ to $100 \%$ and averaged $90 \%$. All disagreements were resolved by consensus.

\section{Results}

For naming accuracy and latency measures, we ran the analyses both by subject (F1) and by item (F2). In all by-subject analyses, maternal education and raw performance IQ scores served as covariates. In all by-item analyses, word length, name agreement, and visual complexity served as covariates.

\section{Naming Accuracy}

By-subject and by-item data were submitted to two separate Group (SLI, AM, VM) $\times$ Word Class (nouns, verbs) mixed-model analyses of covariance (ANCOVAs), with either F1 (proportion of target names produced) or F2 (proportion of children who produced the targets) as the dependent variable. The main effect of group was significant, $F 1(2,37)=$ $6.49, p=.004, \mathrm{\eta}_{\mathrm{p}}^{2}=.26 ; F 2(2,236)=76.83, p<.001, \mathrm{\eta}_{\mathrm{p}}^{2}=.39$. Collapsed across word classes, children in the SLI and VM groups were similarly accurate, and both were less accurate than children in the AM group ( $p s<.001)$. There was a main effect of word class, $F 1(1,39)=$ $131.86, p<.001, \mathrm{\eta}_{\mathrm{p}}^{2}=.77$, and $F 2(1,115)=7.83, p=.006, \eta_{\mathrm{p}}^{2}=.06$, with object naming being more accurate than action naming when the three groups were combined. The Group $\times$ Word Class interaction was also significant, $F 1(2,39)=4.97, p=.01, \eta_{\mathrm{p}}^{2}=.20 ; F 2(2,236)=$ $8.27, p<.001, \eta_{\mathrm{p}}^{2}=.07$. Tukey's honestly significant difference (HSD) tests indicated that object naming was easier than action naming for the children in the SLI and VM groups ( $p$ s $<.05)$, but not for the children in the AM group $(p>.10)$. Ms and SDs of naming accuracy are presented in Table 3.

\section{Naming Latency}

To ensure that the RT data were reliable, we examined latency data retention rate for each individual participant and included only those participants who had at least 20 valid responses (out of 60) for each word condition in the by-subject analyses. Valid responses were accurate and were produced without false triggers. Ten children with SLI, 14 AM peers, and $11 \mathrm{VM}$ peers met this criterion (see Table 1 for demographic information). Hence, RT data from these 35 children were submitted to by-subject analyses. Data retention rate for objects and actions in this reduced participant pool equaled $65 \%$ and $50 \%$ for the SLI group, $78 \%$ and $68 \%$ for the AM group, and $72 \%$ and $58 \%$ for the VM group. Adopting a similar criterion for the by-item analyses, we included only those items for which at least five out of the 14 children in each group provided valid responses. This resulted in $83 \%$ of the object targets and 58\% of the action targets remaining for the analyses.

As seen in Table 3, there was a main effect of word class, $F 1(1,32)=111.63, p<.001$, $\eta_{\mathrm{p}}^{2}=.78 ; F 2(1,80)=43.02, p<.001, \eta_{\mathrm{p}}^{2}=.35$. Object naming was significantly faster than action naming. The effect of group was significant by item only, $F 1(2,30)=0.58, p=.57$,

$\eta_{\mathrm{p}}^{2}=.04 ; F 2(2,166)=16.31, p<.001, \eta_{\mathrm{p}}^{2}=.16$. According to post hoc tests in the by-item analyses, the SLI and VM groups were not different from one another, and both were slower than the AM group $(p s<.001)$. The Group $\times$ Word Class interaction was not significant either by subject or by item. 


\section{Naming Errors}

The total number of naming errors equaled 506 for the SLI children ( 167 for objects and 339 for actions), 478 for the VM children (157 for objects and 321 for actions), and 262 for the AM children (86 for objects, 176 for actions). Table 4 summarizes the breakdown of naming errors into three major categories and 13 subtypes. For each subtype, both the total raw frequency of errors and the mean proportions of errors (calculated by dividing the number of a certain subtype of errors by the total number of errors for each participant and then averaging over the 14 participants in each group) are presented. Because the error data did not meet the requirement of parametric tests, we used Kruskal-Wallis tests to compare error patterns across the three groups and Wilcoxon matched pairs tests to compare error patterns between word classes. The dependent variable in these analyses was the proportion of errors. On the basis of our predictions (see Predictions 2 and 4 ) and guided by the data plots, we conducted statistical tests on the three major categories, GAP verbs, taxonomic errors, misperceptions, misinterpretations, omissions, and unrelated errors. In the paragraphs that follow, we highlight the significant results.

Semantic errors-When the proportions of semantic errors were compared, the only significant difference was that between object and action words, with object naming ( $M=$ $49.9 \%, S E=2.3 \%)$ eliciting more semantic errors than action naming $(M=34.5 \%, S E=$ $2.7 \%, Z=3.91, p<.001, r=.60)$. Given our interest in the use of GAP verbs in children with SLI, we conducted a Kruskal-Wallis analysis of variance (ANOVA) test, with the proportion of GAP verbs as the dependent variable and group as the independent variable. The use of GAP verb substitutions was not different among the three groups $(H=0.60, d f=$ $2, p=.74$; see Table 4 for means). Next, we compared across groups and word classes the rate of taxonomic errors, which included GAP errors, coordinates, and subordinates. This comparison yielded a significant effect of word class $(Z=4.41, p<.001, r=.68)$, with objects $(M=38.1 \%, S E=2.6 \%)$ eliciting more taxonomic errors than actions $(M=21.4 \%$, $S E=2.3 \%)$. In addition, there was a significant group difference in taxonomic errors for object naming $\left(H=7.31, d f=2, p=.03, \eta^{2}=.12\right)$. Post hoc comparisons indicated that the SLI group $(M=29.9 \%, S E=3.8 \%)$ made proportionally fewer taxonomic errors during object naming than the AM group $(M=47.3 \%, S E=4.9 \%)$; the VM group $(M=37.0 \%, S E$ $=3.5 \%$ ) did not differ from either. Thematic errors appeared roughly comparable across groups and word classes and averaged $11.2 \%$ of all errors. Circumlocution errors were rare and averaged $1.2 \%$ of all errors. Therefore, these two subtypes were not analyzed statistically. Patterns of taxonomic, thematic, and circumlocution errors are illustrated in Figure 1.

Visual errors-When visual errors were compared, there was a significant word class effect $(Z=3.92, p<.001, r=.60)$. Visual errors were more common in action naming ( $M=$ $42.3 \%, S E=2.7 \%)$ than in object naming $(M=26.4 \%, S E=2.4 \%)$. This word class effect was true for the SLI and the VM groups ( $Z \mathrm{~s} \geq 2.67, p \mathrm{~s} \leq .008, I \mathrm{~s} \geq .41$ ), but not for the AM group $(Z=1.35, p=.18)$. Next, statistical comparisons were conducted separately for misperception and misinterpretation errors. When misperception errors were compared, the effect of word class was significant $(Z=4.91, p<.001, r=.76)$. Objects $(M=22.1 \%, S E=$ $2.3 \%)$ elicited more misperception errors than actions $(M=7.6 \%, S E=1.1 \%)$. In addition, there was a group effect for action naming $\left(H=10.03, d f=2, p=.007, \mathrm{y}^{2}=.26\right)$. The AM group made proportionally more misperception errors than the SLI and the VM groups when naming actions. The latter two groups did not differ from each other. When misinterpretation errors were compared, the effect of word class was significant $(Z=5.63, p$ $<.001, r=.87)$. Actions $(M=34.7 \%, S E=2.7 \%)$ elicited a much higher proportion of misinterpretation errors than objects $(M=4.2 \%, S E=1.1 \%)$. These patterns are shown in Table 4 and Figure 2. 
Other errors-When the production of other errors was compared, there was an effect of group $\left(H=6.19, d f=2, p=.045, \mathrm{y}^{2}=.18\right)$. The children with SLI $(M=29.4 \%, S E=3.3 \%)$ made more "other" errors than did the AM group $(M=17.9 \%, S E=2.8 \%)$; the VM group $(M=23.2 \%, S E=2.7 \%)$ did not differ from either. This main effect was qualified by a Group $\times$ Word Class interaction: The SLI-AM difference was significant for object naming $\left(H=11.64, d f=2, p=.003, \mathrm{y}^{2}=.26\right)$, but not for action naming $(H=0.72, d f=2, p=.70$; see Table 4 for means). Furthermore, whereas the word class effect was not significant in the SLI and VM groups ( $Z \mathrm{~s} \leq 1.79, p \mathrm{~s} \geq .07)$, in the AM group, actions elicited more "other" errors than did objects $(Z=2.41, p=.02, r=.37)$.

Among the six subtypes of "other" errors, synonyms, novel words (or novel uses of words), purely phonological errors, and perseverations were rare in all children and represented $1.2 \%, 1.6 \%, 1 \%$, and $1.6 \%$ of all errors, respectively. Therefore, these subtypes were not analyzed statistically. When unrelated errors were compared, the word class effect was significant $(Z=2.83, p=.005, r=.44)$. Actions $(M=9.3 \%, S E=1.2 \%)$ elicited more unrelated errors than did objects $(M=4.1 \%, S E=1.3 \%)$. Further, there was a group effect for object naming $\left(H=7.86, d f=2, p=.02, \mathrm{y}^{2}=.20\right)$. The SLI group appeared to have made more unrelated errors when naming objects than did the AM and VM group, although the post hoc comparisons did not reach significance. In addition, actions elicited more unrelated errors than objects in the $\operatorname{AM}(Z=2.41, p=.02, r=.37)$ and VM $(Z=3.02 p=$. $003, r=.47)$ groups but not in the SLI group. When omissions were compared, the word class effect was significant $(Z=2.44, p=.01, r=.38)$, with objects $(M=14.5 \%, S E=2.2 \%)$ eliciting more omissions than actions $(M=8.5 \%, S E=1.5 \%)$. Further, there was a group effect in object naming $\left(H=7.49, d f=2, p=.02, \mathrm{\eta}^{2}=.10\right)$. Post hoc comparisons indicated that the differences between the SLI and the AM groups $(p=.05)$ and between the VM and AM groups $(p=.07)$ were marginally significant, with the SLI and VM groups making more omission errors in object naming than the AM group. Additionally, objects elicited more omissions than actions in the SLI $(Z=1.82, p=.07, r=.28)$ and $\operatorname{VM}(Z=2.48, p=.01, r=$. 38) groups but not in the AM group. Patterns of unrelated and omission errors are presented in Figure 3.

\section{Discussion}

\section{Effects of Language Impairment on Naming Performance}

Naming accuracy and latency-We made several predictions prior to conducting this confrontation naming study. Consistent with our first prediction, the naming accuracy of children with SLI lagged behind that of their AM peers and was similar to that of the younger, VM peers. Naming deficits relative to age mates also characterized groups of children with SLI in previous studies (Lahey\&Edwards, 1999; Leonard et al., 1983; McGregor et al., 2002). The present study is also consistent with Dockrell et al. (2001), who investigated object and action naming in a subgroup of children with SLI-those with WFDs - and found similar naming accuracy in these children as in the naming AM (and receptive grammar-matched) control groups. Taken together, these findings suggest that size of expressive vocabulary rather than chronological age determines the level of naming success. This finding is in line with the storage hypothesis (Kail\&Leonard, 1986) and the unified model of SLI (Rice, 2003) and supports the argument that in the lexical domain, SLI is manifested as a general delay.

We also predicted significant SLI-AM differences in naming latency. This prediction was supported in the by-item analyses, as the SLI group achieved similar latency as the VM group but significantly slower latency than the AM group. The lack of group differences in the by-subject analyses may be due, in part, to the smaller sample size that resulted from limited retention of naming latency data. 
Naming errors-With regard to naming errors, our predictions were generally supported. The children with SLI demonstrated many similarities to the VM and AM peers in the error distribution. In all groups, semantic errors predominated in object naming, and visual errors predominated in action naming. In all groups, taxonomic and misperception errors were more prevalent for object naming, and misinterpretation errors were more prevalent for action naming. These findings indicated that children with SLI did not make bizarre or random naming errors. Instead, the lexical networks in children with SLI are structurally similar to those in typically developing children (McGregor, 1997; McGregor \& Waxman, 1998).

Notwithstanding these similarities, there were several differences in error profiles between the SLI and the AM groups. Specifically, in comparison to the AM children, the children with SLI made more omissions and fewer taxonomic errors when naming objects. They also made more unrelated errors when naming objects, although this difference did not reach statistical significance. As in the accuracy and latency analyses, the SLI and VM groups did not differ on the production of any type of errors.

These patterns are further evidence of vocabulary immaturities in the children with SLI. Previous investigations of children with SLI (McGregor et al., 2002) or children with WFDs (McGregor, 1997) found fewer semantic errors and more unrelated and omission errors in these children than in AM peers. Both of these previous studies suggested that children with SLI (or WFDs) have impoverished semantic representations, which render it difficult to access the appropriate semantic space. In a similar vein, Sheng and McGregor (2010) found that children with SLI — the same children who participated in the present study—generated significantly fewer semantic associations (e.g., spoon-fork) and more unrelated associations (e.g., spoon-Disney) to familiar words than did AM peers, suggesting that the semantic networks in these children are sparsely linked. Together these studies suggest that less elaborated semantic storage and fewer links to semantically related words may be two underlying reasons for these children's naming difficulties. As a result, they resort to strategies such as refusing to label the picture or saying something unrelated.

A further difference in error patterns was that the AM children produced a higher rate of misperception errors in action naming than did the children with SLI. Misperception errors are errors that bear perceptual (but not semantic) similarities with the targets (e.g., shouting/ yawning, pointing/counting, crawling/hiding). These substitutions are usually actions that involve similar body parts and/or body movements. The typically developing children were apparently trying to parse out the most relevant aspects from the picture. Their failed attempts may be a reflection of the inherent ambiguity and fuzziness of verb referents.

Use of GAP verbs-We also predicted that the children with SLI would use a larger number of GAP verbs to substitute for more specific verbs than would the AM children. We did not find support for this prediction, as the number of such substitutions was low and comparable in the three groups of participants. Children in the present study resorted to this strategy to a similarly limited extent, and children with SLI did not overly rely on the use of GAP verbs in confrontation naming. This result stood in contrast to that reported in Dockrell et al. (2001), who found a higher proportion of GAP verb substitutions in children with WFDs than in AM peers. However, the children with language impairment in the study by Dockrell and colleagues were selected based on their deficits in word finding and had an average score of 77.6 on the British Abilities Naming Scale (Elliott, Smith, \& McCulloch, 1997). However, the children with SLI in this study were selected based on measures of grammatical processing, phonological memory, or narrative skills and had a higher average vocabulary $(M=86.4$ on the EVT). It is possible, then, that the overuse of GAP verbs in confrontation naming may be a specific strategy used by children who have relatively severe 
lexical deficits. Alternatively, the lack of differences in GAP verb substitutions in the present study could have been due to the low frequency of these errors as well as the relatively small sample size.

\section{Effects of Word Class}

Consistent with our third prediction, we found strong effects of word class in that object pictures elicited a significantly greater number of accurate responses as well as significantly faster naming latency. Also true to our prediction, we found that this word class effect on naming accuracy was more pronounced in less mature learners-namely, the children with SLI and the VM peers. Although not significant, the same trend was observed in the AM children. It is possible that the near-ceiling performance of the AM group on the object naming task might have prevented the detection of word class difference.

The finding of a main effect of word class indicates that action naming is inherently more difficult than object naming. The Group $\times$ Word Class interaction replicates previous studies (Masterson et al., 2008; Schelletter, 2005) and suggests that the relative difficulty of verbs as compared with nouns may lessen across development, at least for well-practiced and highly familiar words. However, given findings of significant differences in picture naming speed between nouns and verbs in adult naming (Szekely et al., 2005), it is possible that the gap in naming speed between equally accurate nouns and verbs may never close. The finding that the SLI and VM groups demonstrated a comparable noun-verb gap indicates that action naming does not pose undue difficulty for children with SLI. As Rice (2003) has suggested, a selective deficit with verbs is limited to the morphosyntactic domain and is not characteristic of picture naming performance.

In line with our fourth prediction, differences in error patterns in object and action naming were observed. For object targets, the top four most frequent types of errors were taxonomic errors, misperceptions, omissions, and thematic errors. For action targets, the top four error types were misinterpretations, taxonomic errors, thematic errors, and unrelated errors. Furthermore, objects elicited more taxonomic, misperception, and omission errors than did actions, and actions elicited more misinterpretation and unrelated errors than did objects. Therefore, when children were unable to retrieve object names, they were likely to produce a semantic neighbor or associate, a perceptually similar item (e.g., fishing pole for flute, feather for leaf), or a plain refusal. The high occurrence of taxonomic errors is consistent with the hierarchical organization of nouns (McGregor \&Waxman, 1998). The high occurrence of misperception errors suggested that these children were attempting the targets but failed because of the visual resemblance between the targets and other familiar objects. When children were unable to retrieve action names, they also resorted to production of semantic neighbors or associates. However, they also demonstrated many off-task behaviors such as naming objects or other visual aspects of the scene (e.g., piano sound for playing, pretty or girl for smiling) and producing unrelated words. This is consistent with the natural partitions and the linguistic relativity hypotheses (Gentner, 1981, 1982, 2006). Because the semantic and conceptual structures of verbs are inherently more complex and subject to greater possibilities of interpretation, the participants in our study may have found it difficult to identify the intention of the picture (Masterson et al., 2008) or to abide by the intention of the task (by producing a noun or an adjective to an action target).

In summary, evidence from three dependent measures converges and suggests that naming actions is indeed more difficult than naming objects. This finding is consistent with studies of early word learning, which suggest a noun advantage in the sequence and composition of early vocabulary (Bornstein et al., 2004; Gentner, 1982), at least in children acquiring English (Tardif, 1996). This finding is also consistent with studies of word learning in 
preschool and school-age children that demonstrated a gap between noun and verb learning favoring nouns (Alt et al., 2004; Dockrell et al., 2007).

\section{Limitations and Future Directions}

The present study has several limitations. First, although we have reason to believe that the target words are familiar to our participants, we did not probe the children's comprehension of these words or directly measure semantic representation of the words. As a result, we cannot draw strong conclusions about the underlying deficits of naming errors. As we have argued earlier, under elaborated semantic storage and sparsely linked semantic networks are two likely reasons for naming errors. However, it is also likely that some of the naming errors may be caused by lexical gaps - missing representations in the mental lexicon (McGregor et al., 2002). Yet another possible relationship between naming and semantic representation was proposed by Funnell, Hughes, and Woodcock (2006). According to these authors, the ability to name object pictures and to answer questions about these objects develops relatively independently. Specifically, the naming ability of young children (ages $3 ; 7-6 ; 6)$ exceeded their ability to provide answers to questions about the objects. In other words, picture naming in young children does not necessarily depend on detailed underlying semantic representations. Funnell and colleagues suggested that this lack of a relationship may be rooted in the nature of children's early learning experiences. The earliest acquired object labels often are learned through exposure to images in picture books, thereby forging a strong link between a verbal label and its visual representation, sometimes without verbally delivered factual or associated information. Barring evidence to the contrary, we must entertain the possibility that a rich base of semantic knowledge is not a requirement for successful picture naming of early acquired words. Future naming studies may need to include a comprehension probe as well as direct measures of semantic knowledge to gain further insights on what underlies naming ability.

Second, we note that children with SLI are a diverse group, and there is significant variation in the naming abilities of children diagnosed with SLI (Lahey \& Edwards, 1996, 1999; Messer\&Dockrell, 2006). To avoid biasing the results, in the present study, we did not set any criteria on lexical abilities for inclusion in the SLI group, which may have contributed to the heterogeneity of naming performance. In future studies, researchers may consider focusing on subgroups of children with SLI (e.g., children with WFDs) to reduce the variability in the sample and to gain amore in-depth understanding about naming abilities.

Third, similar to previous investigations (Dockrell et al., 2001;Kauschke et al., 2007; Masterson et al., 2008), we used line drawings—which are static representations of actions - to elicit naming responses. This may have contributed to the action naming difficulties. Davidoff and Masterson (1996) used video clips lasting 10-15 s each to depict intransitive and transitive actions and elicited higher naming accuracy and fewer visual errors with these stimuli than with static pictures. This result suggested that drawing inferences about motion from a static representation may be inherently more difficult than identifying objects in a static display. In future investigations, researchers may consider incorporating dynamic presentations of actions to further investigate the effects of stimulus format. However, researchers need to bear in mind that the use of dynamic display poses serious problems for the study of naming latency because the depicted events unfold over time, whereas the depicted objects are present in their entirety from stimulus onset (Szekely et al., 2005).

Fourth, we had a reduced sample size for the naming latency analyses due to low data retention rate, which may have led to the lack of group differences in the by-subject analyses. Data loss was a result of either false triggers or naming errors, with naming errors being the primary factor. To eliminate the impact of false triggers, researchers in future 
studies may consider using analyses of digitized waveforms to obtain latency data. To reduce the number of naming errors, it may be beneficial to pre-train young children on target names.

Finally, we note that nouns and verbs differ not only conceptually but also in various phonological (e.g., stress pattern, word length, number of syllables), lexical (e.g., AoA, word frequency), and semantic (e.g., imageability, concreteness/abstractness) characteristics (Black\&Chiat, 2003;Chen\&Bates, 1998).We controlled for several target characteristics (i.e., AoA, word frequency, familiarity, semantic set size) and included as covariates picture characteristics (i.e., name agreement, objective complexity) and word length. Therefore, we were able to rule out these factors as contributing to the robust word class effect. However, it has been found that other factors-such as imageability and stress pattern-influence children's lexical acquisition (Ma, Golinkoff, Hirsh-Pasek, McDonough, \& Tardif, 2009; Seston et al., 2009) and adults' naming performance (Shaw, 2007). These factors warrant further investigation. In addition, because we included only subclasses of nouns (object entities) and verbs (actions) in the present study, the conclusions concerning word class may not apply to the full range of nouns and verbs but may be specific to the semantic/conceptual distinction between object and action words. Further studies need to systematically investigate various phonological, conceptual, and lexical factors in explaining the core distinction between nouns and verbs.

\section{Conclusion and Clinical Implications}

Despite these limitations, the present study contributes to our understanding of naming abilities in children with SLI. Our results are consistent with the storage hypothesis (Kail\&Leonard, 1986) and the unified model of SLI (Rice, 2003), and they support the view of a general delay in vocabulary development as characteristic of SLI. Picture naming abilities of children with SLI are delayed relative to age peers but are on par with their younger peers who have similar expressive vocabulary levels. The present study also adds to the body of research on verb processing in children with SLI. Our findings are in line with those of Kelly (1997), Thordardottir and Ellis Weismer (2001), and Watkins and colleagues (1993) and suggest that children with SLI do not show disproportionate deficits in verb naming that surpass their general lexical delays.

SLPs should be aware that the child with SLI is likely to present with slower and less accurate naming than his or her peers. Because verbs are more difficult than nouns for everyone, SLPs should expect slower learning of verbs than nouns when teaching, and they should tailor their teaching materials and methods to help the child appreciate the fuzzier perceptual and conceptual boundaries that verbs entail. Moreover, verb usage (as opposed to verb naming) presents more of a challenge than nouns because verbs require specific argument structures and specific markings for tense and finiteness-areas known to be challenging for children with SLI (Eyer et al., 2002; Rice, 2003). That being said, our naming results suggest that it may not be necessary to place special emphasis on verbs over nouns when teaching the child with SLI to link new word forms to their meanings. Instead, both nouns and verbs deserve our attention in clinical teaching programs.

\section{Acknowledgments}

This work was supported by National Institute on Deafness and Other Communication Disorders Grant 2 R01 DC003698-06, awarded to the second author. Portions of these data were presented at the 29th Annual Symposium on Research in Child Language Disorders in Madison, WI. We thank the children and their families who participated in this study. 


\section{References}

Alt M, Plante E, Creusere M. Semantic features in fast-mapping: Performance of preschoolers with specific language impairment versus preschoolers with normal language. Journal of Speech, Language, and Hearing Research. 2004; 47:407-420.

Ameel E, Malt B, Storms G. Object naming and later lexical development: From baby bottle to beer bottle. Journal of Memory and Language. 2008; 58:262-285.

Bates E, Marchman VA, Thal D, Fenson L, Dale P, Reznick JS, Hartung J. Development and stylistic variation in the composition of early vocabulary. Journal of Child Language. 1994; 21:85-123. [PubMed: 8006096]

Black M, Chiat S. Noun-verb dissociations: A multi-faceted phenomenon. Journal of Neurolinguistics. 2003; 16:231-250.

Bornstein MH, Cote LR, Maital S, Painter K, Park S-Y, Pascual L, Vyt A. Cross-linguistic analysis of vocabulary in young children: Spanish, Dutch, French, Hebrew, Italian, Korean, and American English. Child Development. 2004; 75:1115-1139. [PubMed: 15260868]

Carroll JB, White MN. Word frequency and age of acquisition as determiners of picture-naming latency. Quarterly Journal of Experimental Psychology. 1973; 23:85-95.

Chen S, Bates E. The dissociation between nouns and verbs in Broca's and Wernicke's aphasia: Findings from Chinese. Aphasiology. 1998; 12:5-36.

Childers J, Tomasello M. Two-year-olds learn novel nouns, verbs, and conventional actions from massed or distributed exposures. Developmental Psychology. 2002; 38:967-978. [PubMed: 12428708]

Conti-Ramsden G, Jones M. Verb use in specific language impairment. Journal of Speech, Language, and Hearing Research. 1997; 40:1298-1313.

Davidoff J, Masterson J. The development of picture naming: Differences between verbs and nouns. Journal of Neurolinguistics. 1996; 9:69-83.

Dockrell JE, Braisby N, Best RM. Children's acquisition of science terms: Simple exposure is insufficient. Learning and Instruction. 2007; 17:577-594.

Dockrell J, Messer D, George R. Patterns of naming objects and actions in children with word-finding difficulties. Language and Cognitive Processes. 2001; 16:261-286.

Elliott, CD.; Smith, P.; McCulloch, K. The British Ability Scales-II. Windsor, United Kingdom: nferNelson; 1997.

Ellis Weismer S, Evans JL. The role of processing limitations in early identification of specific language impairment. Topics in Language Disorders. 2002; 22:15-29.

Eyer JA, Leonard LB, Bedore LM, McGregor KK, Anderson B, Viescas R. Fast mapping of verbs by children with specific language impairment. Clinical Linguistics \& Phonetics. 2002; 16:59-77. [PubMed: 11913032]

Fenson L, Dale PS, Reznick JS, Bates E, Thal DJ, Pethick SJ. Variability in early communicative development. Monographs of the Society for Research in Child Development. 1994; 59(Serial No. 242)

Funnell E, Hughes D, Woodcock J. Age of acquisition for naming and knowing: A new hypothesis. Quarterly Journal of Experimental Psychology. 2006; 59:268-295.

Gentner D. Some interesting differences between nouns and verbs. Cognition and Brain Theory. 1981; 4:161-178.

Gentner, D. Why nouns are learned before verbs: Linguistic relativity versus natural partitioning. In: Kuczaj, SA., editor. Language development: Vol. 2. Language, thought and culture. Hillsdale, NJ: Erlbaum; 1982. p. 301-334.

Gentner, D. Why verbs are hard to learn. In: Hirsh-Pasek, K.; Golinkoff, R., editors. Action meets word: How children learn verbs. Oxford, United Kingdom: Oxford University Press; 2006. p. 544-564.

German, DJ. Test of Word Finding. Austin, TX: Pro-Ed.; 1989.

Gleitman L. The structural sources of verb meanings. Language Acquisition. 1990; 1:3-55. 
Imai M, Li L, Haryu E, Okada H, Hirsh-Pasek K, Golinkoff RM, Shigematsu J. Novel noun and verb learning in Chinese-, English-, and Japanese-speaking children. Child Development. 2008; 79:979-1000. [PubMed: 18717902]

Jackson-Maldonado D, Thal D, Marchman V, Bates E, Gutierrez-Clellen V. Early lexical development in Spanish-speaking infants and toddlers. Journal of Child Language. 1993; 20:523-549. [PubMed: 8300774]

Kail R, Leonard LB. Word-finding abilities in children with specific language impairment. Monographs of the American Speech-Language-Hearing Association. 1986; 25

Kaufman, AS.; Kaufman, NL. The Kaufman Brief Intelligence Test. Circle Pines, MN: AGS; 2003.

Kauschke C, Lee H-W, Pae S. Similarities and variation in noun and verb acquisition: A crosslinguistic study of children learning German, Korean, and Turkish. Language and Cognitive Processes. 2007; 22:1045-1072.

Kelly DJ. Patterns in verb use by preschoolers with normal language and specific language impairment. Applied Psycholinguistics. 1997; 18:199-218.

Kim M, McGregor KK, Thompson CK. Early lexical development in English- and Korean-speaking children: Language-general and language-specific patterns. Journal of Child Language. 2000; 27:225-254. [PubMed: 10967886]

Lahey M, Edwards J. Why are children with specific language impairment slower than their peers in naming pictures? Journal of Speech and Hearing Research. 1996; 39:1081-1098. [PubMed: 8898260]

Lahey M, Edwards J. Naming errors of children with specific language impairment. Journal of Speech, Language, and Hearing Research. 1999; 42:195-205.

Leonard LB, Nippold MA, Kail R, Hale C. Picture naming in language impaired children. Journal of Speech and Hearing Research. 1983; 26:609-615. [PubMed: 6668948]

Leonard, LB.; Schwartz, R. Early linguistic development of children with specific language impairment. In: Nelson, KE., editor. Children's language. Vol. Vol. 5. Hillsdale, NJ: Erlbaum; 1985. p. 291-318.

Ma WY, Golinkoff RM, Hirsh-Pasek K, McDonough C, Tardif T. Imageability predicts the age of acquisition of verbs in Chinese children. Journal of Child Language. 2009; 36:405-423. [PubMed: 18937878]

Masterson J, Druks J, Gallienne D. Object and action picture naming in three- and five-year-old children. Journal of Child Language. 2008; 35:373-402. [PubMed: 18416864]

McGregor KK. The nature of word-finding errors of preschoolers with and without word-finding deficits. Journal of Speech, Language, and Hearing Research. 1997; 40:1232-1244.

McGregor KK, Newman RM, Reilly RM, Capone N. Semantic representation and naming in children with specific language impairment. Journal of Speech, Language, and Hearing Research. 2002; 45:998-1014.

McGregor KK, Waxman S. Object naming at multiple hierarchical levels: A comparison of preschoolers with and without word-finding deficits. Journal of Child Language. 1998; 25:419_ 430. [PubMed: 9770914]

Messer D, Dockrell JE. Children's naming and word finding difficulties: Descriptions and explanations. Journal of Speech, Language, and Hearing Research. 2006; 49:309-324.

Moe, A.; Hopkins, C.; Rush, T. The vocabulary of first-grade children. Springfield, IL: Charles C Thomas; 1982.

Montgomery JW. Understanding the language difficulties of children with specific language impairments: Does verbal working memory matter? American Journal of Speech-Language Pathology. 2002; 11:77-91.

Morrison CM, Chappell TD, Ellis AW. Age of acquisition norms for a large set of object names and their relation to adult estimates and other variables. Quarterly Journal of Experimental Psychology. 1997; 50:528-559.

Nelson DL, McEvoy CL, Schreiber TA. The University of South Florida word association, rhyme, and word fragment norms [Database]. 1998 Retrieved from http://w3.usf.edu/FreeAssociation. 
Nusbaum, HC.; Pisoni, DB.; Davis, CK. Research on speech perception. Bloomington: Indiana University Press; 1984. Sizing up the Hoosier Mental Lexicon: Measuring the familiarity of 20,000 words; p. 357-376.[Progress Report 10]

Oetting JB, Rice J, Swank LK. Quick incidental learning (QUIL) of words by school-age children with and without SLI. Journal of Speech and Hearing Research. 1995; 38:434-445. [PubMed: 7596109]

Psychology Software Tools. E-Prime (Version 1.1) [Computer software]. Pittsburgh, PA: Author; 2002.

Rice, M. A unified model of specific and general language delay: Grammatical tense as a clinical marker of unexpected variation. In: Levy, Y.; Schaeffer, J., editors. Language competence across populations: Toward a definition of specific language impairment. Mahwah, NJ: Erlbaum; 2003. p. 63-95.

Rice M, Bode J. GAPS in the verb lexicons of children with specific language impairment. First Language. 1993; 13:113-131.

Rice ML, Buhr JC, Nemeth M. Fast mapping word-learning abilities of language-delayed preschoolers. Journal of Speech and Hearing Disorders. 1990; 55:33-42. [PubMed: 2299838]

Schelletter, C. Lexical skills in English monolingual children: Differences between nouns and verbs. Poster presented at the 10th International Congress for the Study of Child Language; Berlin, Germany. 2005 Jul.

Seston R, Golinkoff RM, Ma WY, Hirsh-Pasek K. Vacuuming with my mouth? Children's ability to comprehend novel extensions of familiar verbs. Cognitive Development. 2009; 24:113-124. [PubMed: 20161104]

Shaw, VC. The effect of grammatical class and lexical stress on word retrieval in aging and aphasia. University of Iowa; Iowa City, IA. 2007. (Unpublished doctoral dissertation)

Sheng L, McGregor KK. Lexical semantic organization in children with specific language impairment. Journal of Speech, Language, and Hearing Research. 2010; 53:146-159.

Sheng L, McGregor KK, Marian V. Lexical-semantic organization in bilingual children: Evidence from a repeated word association task. Journal of Speech, Language, and Hearing Research. 2006; 49:572-587.

Szekely A, D’Amico S, Devescovi A, Federmeier K, Herron D, Iyer G, Bates E. Timed action and object naming. Cortex. 2005; 41:7-25. [PubMed: 15633703]

Szekely A, Jacobsen T, D’Amico S, Devescovi A, Andonova E, Herron D, Bates E. A new on-line resource for psycholinguistic studies. Journal of Memory and Language. 2004; 51:247-250.

Tardif T. Nouns are not always learned before verbs: Evidence from Mandarin speakers' early vocabularies. Developmental Psychology. 1996; 32:492-504.

Tardif T, Gelman SA, Xu F. Putting the "noun bias" in context: A comparison of English and Mandarin. Child Development. 1999; 70:620-635.

Thordardottir ET, Ellis Weismer S. High-frequency verbs and verb diversity in the spontaneous speech of school-age children with specific language impairment. International Journal of Language and Communication Disorders. 2001; 36:221-244. [PubMed: 11344596]

Tomasello M, Kruger AC. Joint attention on actions: Acquiring verbs in ostensive and non-ostensive contexts. Journal of Child Language. 1992; 19:311-333. [PubMed: 1527205]

Watkins R, Rice M, Moltz C. Verb use by language-impaired and normally developing children. First Language. 1993; 13:133-143.

Williams, KT. Expressive Vocabulary Test. Circle Pines, MN: AGS; 1997.

Windsor J. Contrasting general and process-specific slowing in language impairment. Topics in Language Disorders. 2002; 22:49-61. 


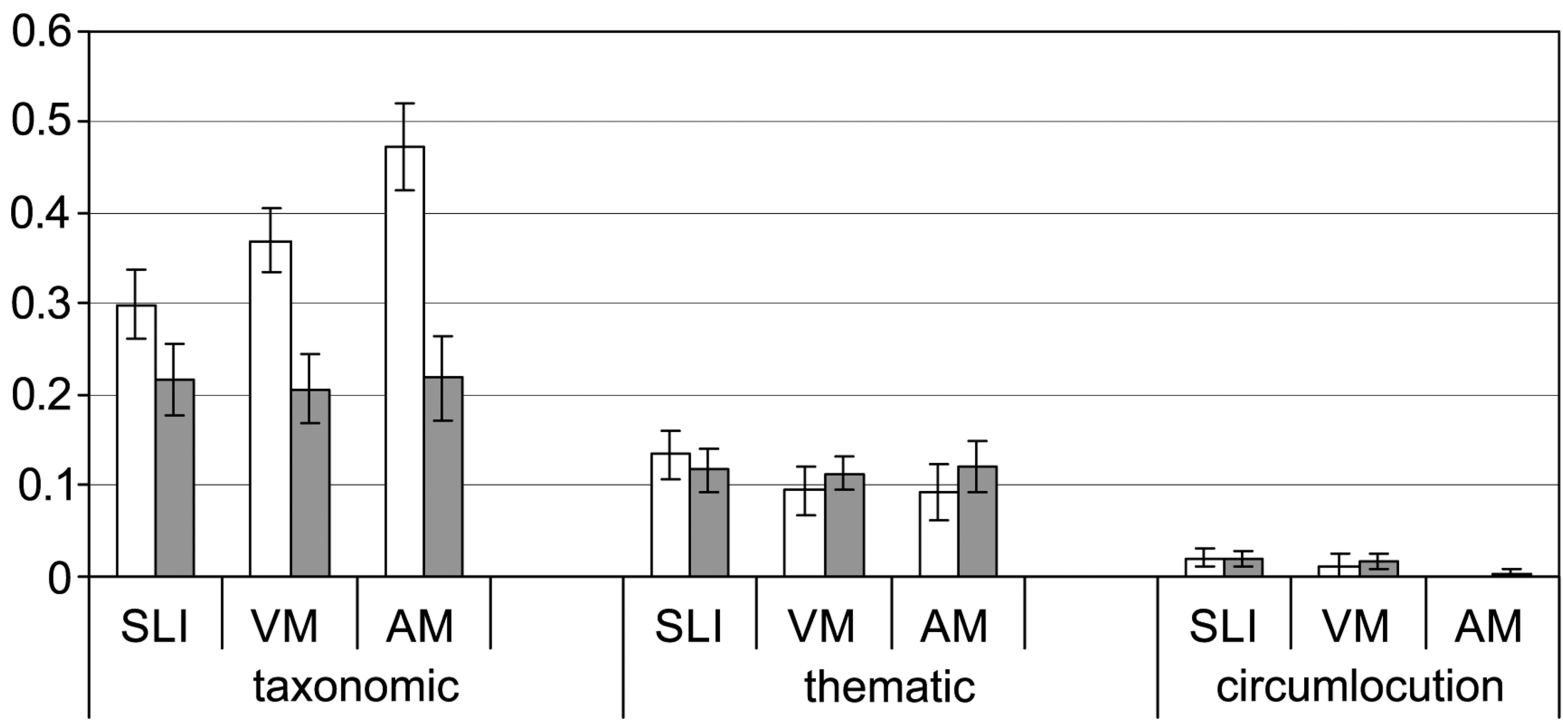

Figure 1.

Mean proportion of taxonomic, thematic, and circumlocution errors, by group and word class. Error bars denote standard errors. SLI = children with specific language impairment; $\mathrm{VM}=$ vocabulary-matched controls; $\mathrm{AM}=$ age-matched controls. 


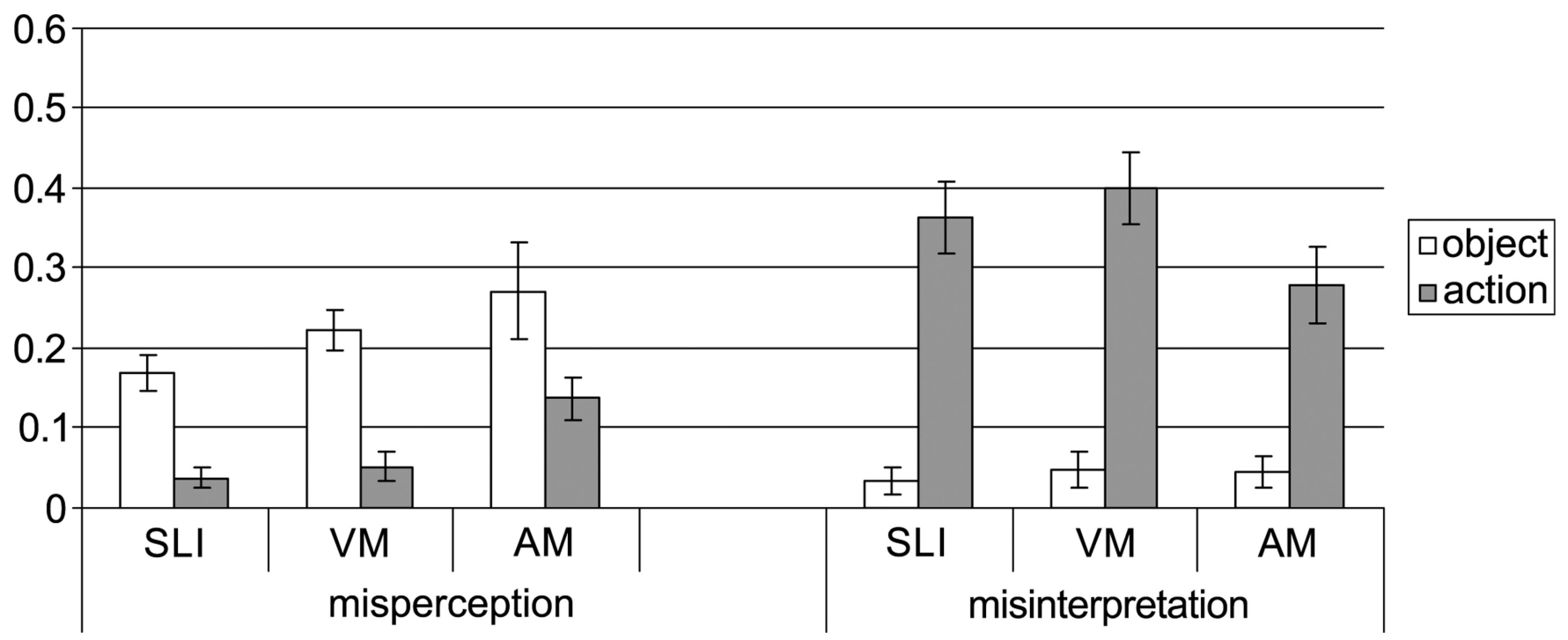

Figure 2.

Mean proportion of misperception and misinterpretation errors, by group and word class. 


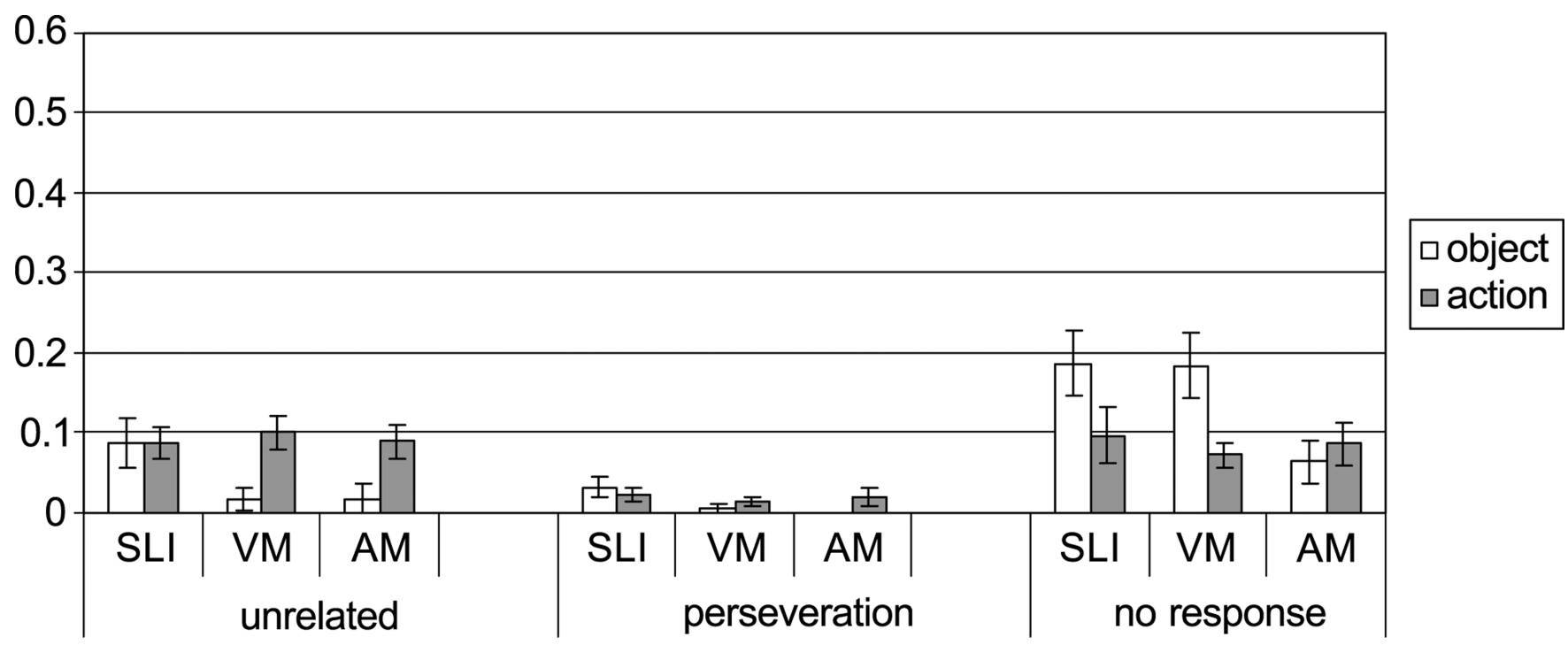

Figure 3.

Mean proportion of unrelated and omission errors, by group and word class. 


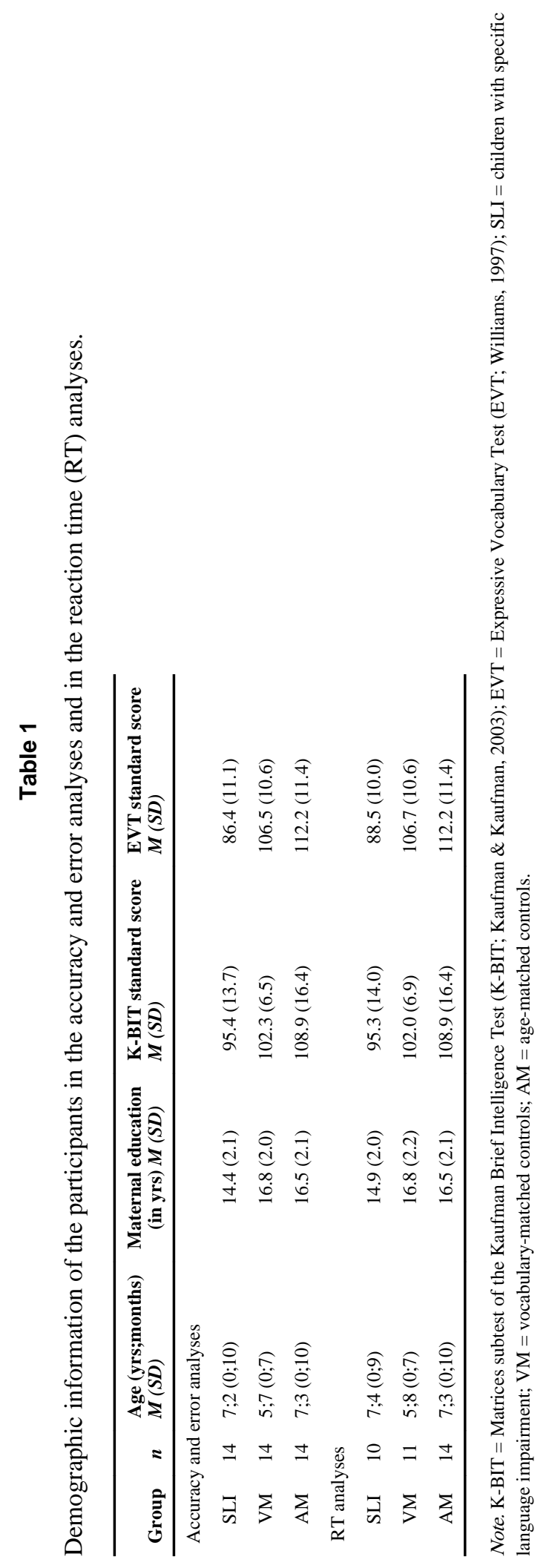

J Speech Lang Hear Res. Author manuscript; available in PMC 2012 June 08. 


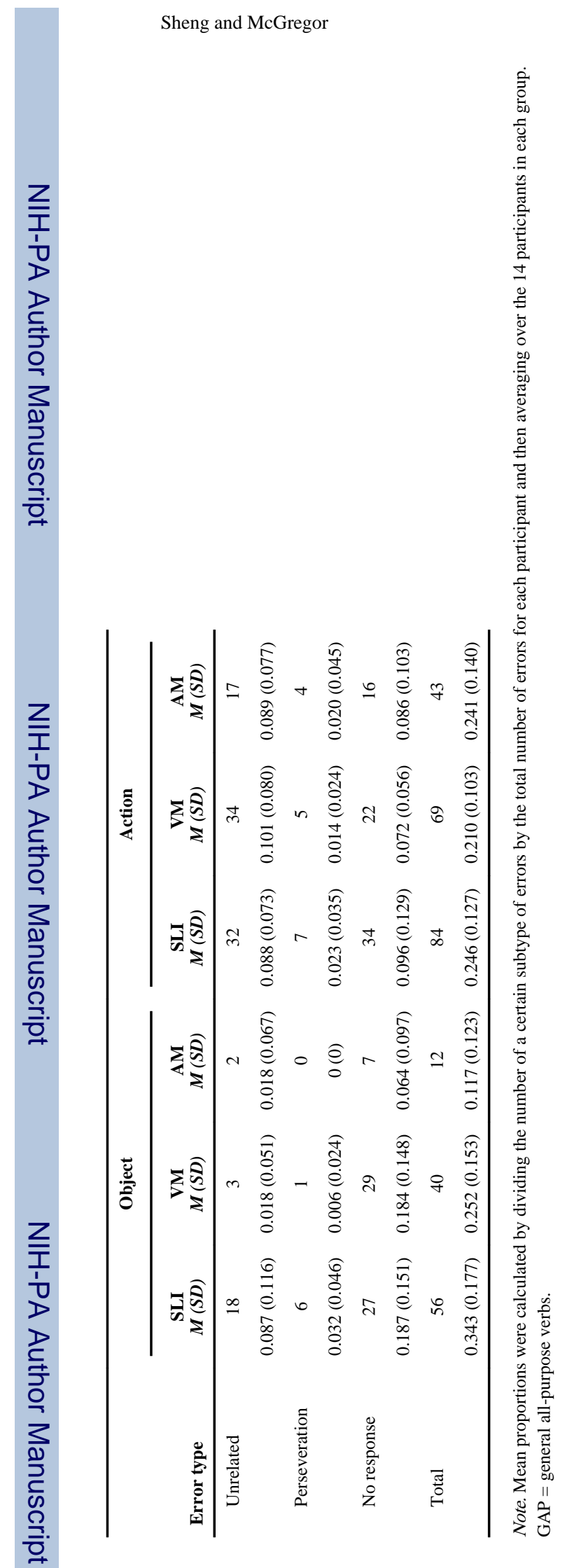

J Speech Lang Hear Res. Author manuscript; available in PMC 2012 June 08. 